\title{
藏北高原草地生态治理与畜牧业协同发展模式研究
}

\author{
干珠扎布 ${ }^{1}$, 胡国铮 ${ }^{1}$, 高清竹 $^{1}$, 江村旺扎 $^{2}$, 旦久罗布 ${ }^{2}$, 参木友 $^{3}$, 巴桑旺堆 ${ }^{3}$, \\ 杨富裕 ${ }^{4}$, 魏学红 $^{5}$, 杨永平 $^{6}$
}

(1. 中国农业科学院农业环境与可持续发展研究所, 北京 100081；2. 那曲市草原站, 西藏那曲 852000;

3. 西藏自治区农牧科学院，拉萨 $850000 ；$. 中国农业大学草地研究所，北京 100193;

5. 西藏农牧学院, 西藏林芝 860000；6. 中国科学院昆明植物研究所, 昆明 650201)

摘要: 藏北高原是我国重要的生态安全屏障和高原特色畜牧业基地, 而高寒草地退化严重制约着其生态和生产功能, 给生态 保护和畜牧业发展带来了挑战。本文在深入分析藏北高原生态治理与畜牧业发展状况的基础上，探讨了藏北高寒草地生态与 生产功能的主要影响因素, 提出了藏北高原草地生态治理与畜牧业协同发展的模式体系。研究表明, 通过草地生态恢复、优 化放牧管理方式、人工牧草种植、低海拔农区种草高海拔牧区养畜的 “低草高牧” 模式、冬季半舍饲养殖等一系列措施, 能 够推进高寒草地生态功能提升、促进草地畜牧业转型升级, 实现 “保护中发展”与 “发展中保护”。相关研究将为治边稳藏、 保障国家生态安全、增加牧民收入提供战略引导和科技支撑。

关键词: 藏北高原; 生态修复; 草地畜牧业; 协同发展

中图分类号: S 812.8

文献标识码: A

\section{Synergetic Mode for Grassland Ecological Management and Animal Husbandry Development in Northern Tibet Plateau}

\author{
Hasbagan Ganjurjav ${ }^{1}$, Hu Guozheng ${ }^{1}$, Gao Qingzhu ${ }^{1}$, Jiangcun Wangzha ${ }^{2}$, Danjiu Luobu ${ }^{2}$, \\ Can Muyou ${ }^{3}$, Basang Wangdui ${ }^{3}$, Yang Fuyu ${ }^{4}$, Wei Xuehong ${ }^{5}$, Yang Yongping ${ }^{6}$
}

(1. Institute of Environment and Sustainable Development in Agriculture, Chinese Academy of Agricultural Sciences, Beijing 100081, China; 2. Nagqu Grassland Station, Nagqu 852000, Tibet, China; 3. Tibet Academy of Agricultural and Animal Husbandry Sciences, Lhasa 850000, China; 4. Grassland Institute, China Agricultural University, Beijing 100193, China;

5. Tibet Agriculture \& Animal Husbandry University, Nyingchi 860000, Tibet, China;

6. Kunming Institute of Botany, Chinese Academy of Sciences, Kunming 650201, China)

\begin{abstract}
Northern Tibet Plateau is an important ecological security shelter for China and a base of animal husbandry with plateau characteristics. However, grassland degradation is threatening the functioning of alpine grasslands and brings great challenges to ecological protection and animal husbandry development. In this study, we analyzed the current situation of ecological protection and animal husbandry development in the Northern Tibet Plateau, summarized the factors affecting the functions of alpine grasslands in this
\end{abstract}

收稿日期 : 2019-08-09; 修回日期 : 2019-09-12

通讯作者: 高清竹, 中国农业科学院农业环境与可持续发展研究所研究员, 主要研究方向为气候变化与草地生态; E-mail: gaoqingzhu@caas.cn 资助项目：中国工程院咨询项目 “生态文明建设若干战略问题研究（三期）” (2017-ZD-09); 国家重点研发计划项目 (2016YFC0502003) 本刊网址：www.engineering.org.cn/ch/journal/sscae 
region, and introduced a synergistic mode for grassland ecological protection and animal husbandry development. A series of measures were also proposed to enhance the ecological functions of the alpine grasslands and upgrade the grassland-based animal husbandry, including ecological restoration of degraded grasslands, optimizing grazing management, artificial forage cultivation, developing a "low grass and high grazing" mode (i.e., planting grass in farming areas of low altitude and raising livestock in pastoral areas of high altitude), and half barn-feeding in winter. This study is hoped to provide scientific and technological support in ensuring national ecological security and increasing income of herdsmen.

Keywords: Northern Tibet Plateau; ecological restoration; grassland-based animal husbandry; synergetic development

\section{一、藏北高原概况}

藏北高原位于青藏高原的腹地，是 “世界屋 脊” “亚洲水塔” “地球第三极” 的核心区域，平均 海拔 $4500 \mathrm{~m}$ 以上, 南起冈底斯山脉、念青唐古拉 山脉，北至喀喇昆仑山脉、可可西里山脉。藏北高 原在行政区域上与西藏自治区那曲市重合, 面积为 $4.46 \times 10^{5} \mathrm{~km}^{2}$, 是我国重要的生态屏障区和水资源 战略保障基地。藏北高寒草地面积为 $4.21 \times 10^{5} \mathrm{~km}^{2}$, 占藏北高原总面积的 $94.4 \%$, 约占西藏草地总面积 的 $1 / 2$ [1]。

藏北高寒草地是藏族牧民赖以生存的物质基 础, 是我国高原特色畜牧业基地之一。虽然藏北高 原草地面积广阔, 但限于特殊的生态环境, 大部分 草地生产力较低; 加之生长季短、冬季漫长、冬春 季饲草供应严重不足, 制约了传统草地畜牧业发展。 从 1958 年至今, 藏北高原总人口和牧业人口均呈 显著升高态势。截至 2015 年年底, 藏北总人口由 1958 年的 8.39 万人增长至 50.13 万人，其中牧业人 口为 43 万人, 占总人口的 $86 \%$, 近 $1 / 4$ 的牧民仍 处于贫困状态。而随着人口数量的激增, 藏北高原 牲畜数量也大幅增加, 2015 年年底藏北各类牲畜存 栏约 1300 万羊单位。

藏北高寒草地生态与生产的功能对我国生态安 全、边疆社会稳定和牧民生存发展至关重要。但近 几十年, 在气候变化加剧、人口激增和牲畜数量增 加等一系列因素影响下, 藏北高寒草地大范围退化, 严重制约了藏北高原生态安全屏障作用和社会经济 可持续发展。进入 21 世纪, 随着国家生态保护和 生态文明建设的大力推进, 藏北高原草地退化趋势 得到了初步遏制, 退化草地获得一定程度上的恢复。 然而, 当地资源开发利用受到进一步限制, 生态保 护与草地畜牧业发展之间的矛盾日益突出, 将影响 到当地牧民脱贫进程和国家乡村振兴战略的实施。
在保护生态的同时全面处理好改善民生和发展社会 经济过程中的诸多难题, 成为藏北高原建设与发展 中面临的重要任务和挑战。在保护中发展、发展中 保护, 既是藏北高原绿色发展的强烈需求, 也是社 会主义新时代对藏北高原提出的建设要求。因此, 生态治理与畜牧业协同发展是藏北高原的必然选择 和必由之路。

\section{二、藏北高原草地生态与畜牧业发展现状}

\section{（一）藏北高原草地现状}

近几十年来，藏北高寒草地出现了不同程度的 退化。遥感监测结果显示, 截至 2010 年, 藏北高 原草地退化面积比例达到 $58.2 \%$, 整体接近中度退 化水平。与 20 世纪 80 年代相比, 藏北高原重度与 极重度退化草地面积有所增加, 草地退化情况仍不 容忽视。草地退化是包括自然因素和人为因素在内 的多种因素综合作用的结果。自然因素有气候变化、 鼠害、虫害等, 人为因素有放牧、采矿、开垦等。 多重因素的叠加造成了藏北高寒草地大面积退化, 一般认为气候变化和超载过牧是主要驱动力 [2]。

气候是决定植被分布的关键因素, 藏北高原独 特的气候条件决定了该地区特殊的植被类型。在高 寒、缺氧、雨热同季的气候条件下, 藏北高原植物 普遍低矮, 抗寒性和抗旱性较强。近几十年来, 藏 北高原气候发生了明显的改变, 表现出温度升高、 降水增加的趋势; 但由于增温导致蒸发强烈, 因此 藏北高原气候整体趋于暖干化。此外, 高原气候变 化存在季节非对称性, 即秋冬季增温幅度大于春夏 季, 而降水增加则主要来源于冬春季, 夏季甚至呈 现降水减少, 生长季干旱加剧。由于气候变化引起 季节性干旱, 高寒草地中适合湿冷生态环境的草甸 植物将减少, 而被中生化耐旱的禾本科牧草替代, 高寒草地可能向中生化演替。以增温为主要特征的 
气候变化有可能导致生产力降低、优良牧草比例减 少、毒草滋生, 增加草地退化风险 [3]。因此, 气 候变化对草地生态系统的负面影响不容忽视。

适度放牧有利于草地生态系统稳定, 而过度放 牧将导致草地退化。自 20 世纪 50 年代起藏北地区 家畜数量逐步增加, 从 20 世纪 90 年代开始数量有 所下降，但目前仍处于较高水平 [4]。人口和家畜 数量的增加, 为藏北高寒草地生态系统带来了巨大 压力。在放牧强度过大时, 植物的补偿生长作用远 低于被牲畜采食的牧草量, 从而使草地生产力降低。 由于牲畜选择性采食的原因, 重牧条件下优良牧草 比例显著降低。过度放牧条件下牲畜践踏对高寒草 地植被和土壤也具有一定的破坏性。此外, 鼠害亦 是藏北高原草地退化的主要原因之一, 使得草地生 产力降低、优良牧草比例减少、土壤裸露、水土保 持能力下降。

\section{（二）藏北高原畜牧业发展现状}

藏北高原自古以来是藏族牧民赖以生存的放牧 场, 是西藏自治区的主要畜牧业生产基地, 草地面 积、牲畜存栏数量、畜产品产量均占全区的 $1 / 3$ 以 上。畜牧业占藏北国民经济收入的 $80 \%$ 以上，畜 牧业经济的发展在一定程度上反映了藏北经济发展 水平。藏北高原家畜以牦牛和藏羊为主, 牦牛集中 在东部草甸区, 藏羊多在西部草原区。藏北草地畜 牧业独具高原特色, 牦牛乳制品和肉产品产业的发 展潜力巨大。

截至 2015 年年底, 藏北高原各类牲畜存栏数 为 525.47 万头 (只、匹), 较 1958 年增加了 $117 \%$ [1], 牲畜数量居高不下。而藏北高原草地生产力普遍较 低, 难以为藏北畜牧业提供足够的牧草。此外, 随 着天然草原承包到户，原有的游牧方式被定点放牧 取代，使草地不能休养生息，草地的放牧压力进一 步加大。目前, 藏北高原草地生态系统处于超载过 牧状态, 放牧压力超过了其承载能力, 系统处于不 可持续的发展状态 [5]。

藏北高原气候温度低, 全年无绝对无霜期, 冬 季寒冷漫长且灾害多发; 牧草生长季短、植被生产 力低, 牧草尤其是冬季饲草缺口巨大。由于藏北草 地生产力季节差异显著, 牲畜呈“夏壮、秋肥、冬瘦、 春乏” 的季节动态变化, 冬季体重减少近 $30 \%$, 夏 季又恢复到原有水平; 牲畜繁殖期处于冬春季饲草
短缺时期, 具有低繁殖率和低幼㩄成活率的特点, 大大降低了再生产性能。目前, 藏北高原畜牧业仍 以 “靠天养畜” 为主, 缺乏科学的养殖技术支撑, 抵御灾害和风险能力较差, 畜牧业生产效率低下, 传统草地畜牧业亟待转型升级。因此, 低温、低产、 低效是制约藏北高原草地畜牧业发展的主要因素。

\section{三、藏北高原草地生态治理与畜牧业协同发 展模式}

藏北高原草地生态治理与畜牧业协同发展的关 键在于守住 “保护” 和 “发展” 两条底线, 实现保 护中发展和发展中保护。高寒草地治理是藏北发展 的基础, 采用一系列草地保护、修复技术和政策措 施, 促进天然草地保护、恢复, 提升其生态功能, 保障国家生态安全。在草地治理的基础上, 主导发 展生态畜牧业, 完成传统畜牧业转型升级, 促进牧 民增收，为打赢脱贫攻坚战、治边稳藏提供支撑。

\section{（一）草地生态恢复}

\section{1. 生态补播}

对于退化草地植被覆盖度低、土壤裸露等问题, 简单的自然恢复难以起到良好的效果。采用常见的 高寒抗逆物种进行补播, 能够有效恢复植被盖度、 提高草地生产力。将垂穗披碱草、多叶老芒麦、冷 地早熟禾等上繁草种和下繁草种以及快速定植和慢 速定植植物相结合, 在裸露的退化草地进行补播, 保证出苗延续性和保护性以及植被建成后群落结构 合理 [6,7]。适当加大播种密度, 保证越冬后可更新 的幼苗数量。

\section{2. 节能灌溉}

藏北高原蒸发强烈, 全年蒸发量超过 $1500 \mathrm{~mm}$, 且雨季主要集中在相对高温的 5 9 月 [1]。一方面, 随着气候变化加剧, 藏北高原面临较大的季节性干 旱风险, 增加了退化草地治理难度; 另一方面, 由 于温度升高, 雪山和冰川融化, 导致地表径流量增 加、河流水位上涨, 为周边区域退化草地提供了水 源。因此, 充分利用河流、湖泊等地表水资源, 发 挥藏北高原风能、太阳能丰富的优势, 研发和应 用高寒草地风光互补节能喷灌技术, 增加草地生 产力的同时提高物种多样性，显著提升高寒草地 生态功能 [8]。 
3. 施肥

土壤贫痊是退化高寒草地的主要表征之一。恢 复退化草地, 施肥往往被视为行之有效的方法。牛 羊粪等有机肥和氮磷混施可以作为藏北高原退化高 寒草地恢复的主要施肥方案 $[9,10]$ 。无机肥可以被 植物迅速吸收, 达到速效肥的效果; 单纯施氮肥可 能会造成草地养分失衡 [11], 而氮磷混施对退化草 地恢复效果良好 [10,12]。有机肥分解慢、作用时间 长, 可以提供足够的碳、氮源, 供土壤微生物代谢 为植物提供养分, 达到缓释肥的效果。施入有机肥 还可以提高碳氮比, 可在短期内控制杂草生长。

\section{（二）草地优化管理}

\section{1. 禁牧}

对退化草地而言, 禁牧可以减少扰动, 让草地 休养生息, 对草地恢复起到良好的效果。但禁牧不 能是无休止的, 长期的禁牧有可能对草地生态系统 产生负面影响, 阻碍植物生长, 导致物种多样性降 低 $[13,14]$ 。根据草地退化程度及其生态环境特点, 因地制宜地制定合理的禁牧年限, 是保护草地、优 化草地管理和利用的最佳方式。对藏北高原不同年 限的禁牧草地调查结果显示, 5 7 年是该区域较为 合理的禁牧年限 [15]。

\section{2. 休牧}

高寒草地生产力普遍较低, 而全年放牧对草地 形成巨大压力。适度划分冬季牧场和夏季牧场, 采 取季节性休牧, 有利于减轻草地压力, 促进草地生 态系统生态与生产功能提升。可以将藏嵩草、青藏 苔草等为建群种的高产草地设置为冬季牧场, 将小 嵩草、紫花针茅等为建群种的低产草地设置为夏季 牧场, 以达到资源合理利用和最优配置。此外, 也 可以选取一年中牧草生长的关键期, 如在返青期进 行休牧, 可达到事半功倍的效果 [16]。

\section{3. 轮牧}

将草地划分为若干小区, 并依次进行放牧活动, 既可以保护天然草地又可以提高草地利用率。由于 藏北高原草地生产力较低, 以草定畜是草地保护和 畜牧业发展的关键。藏北高原放牧强度不宜超过 1.2 羊单位 $/ \mathrm{hm}^{2}$, 轮牧时间以 7 10 d 为宜。该措施 是一种生态和生产兼顾的方式, 草地生产力不仅达 到最优, 并且牲畜采食量、草地利用率以及物种多 样性均较高 [17]。

\section{（三）牧草多源供给}

\section{1. 区域化种草}

重度退化草地, 如 “黑土滩” 型退化草地, 丧 失了生态和生产功能。在这类草地进行区域化人工 草地建植, 既可以修复草地, 又可以提供牧草, 达 到双赢的效果 [18]。在藏北高原, 应重点挖掘本土 优质牧草潜力, 开发高产牧草种质资源, 巩固现有 推广应用效果良好的冷地早熟禾、星星草、老芒麦、 垂穗披碱草、紫羊茅、无芒雀麦、箭舌踠豆、黄 花草木樨等品种 [6]; 建设人工牧草基地以及灌溉、 施肥等配套设施, 为畜牧业提供稳定的牧草供应源。

\section{2. 庭院种草}

牧户庭院和牲畜棚圈主要用于冬季牲畜保暖, 而夏季为闲置空间, 具有热量充足、水分条件好、 土壤肥力高等特点。因此, 充分发挥牧户庭院和牲 畜棚圈有利的水热肥条件以及便于管理的优势, 开 展生长季庭院和棚圈种草, 以生产优质牧草。青稞 作为西藏本土物种, 生产力和营养价值均较高, 适 宜在高寒牧区庭院和牲畜圈棚内播种。此外, 充分 利用棚圈、房屋已有的墙体或其他遮挡物, 建造简 易温室大棚用于牧草种植, 可常年供应牧草。

\section{3. 农区种草}

与藏北高原相比, 西藏农区海拔低、气候条件 好、植物生产力高; 相较牧民, 农民对作物种植及 其配套技术更为熟悉。因此，在西藏农区种植的饲 用青稞和饲用燕麦等适口性较强的一年生牧草, 运 至高寒牧区用于冬季补饲, 形成农牧耦合的 “低草 高牧” 模式，不仅使农区和牧区群众增收，并且可 以带动物流、牧草种植企业发展壮大, 促进跨区域、 跨行业共同发展。

\section{（四）牲畜半舍饲养殖}

目前, 西藏高原仍以 “靠天养畜” 为主, 在传 统的放牧方式下, 漫长、寒冷的冬季对草地畜牧业 带来一系列影响, 导致牲畜掉膘、死亡, 造成经济 损失。在藏北高原, 可以采用冬季半舍饲模式, 调 整畜群结构, 优化补饲保暖的养殖方式, 全面提升 草地畜牧业生产能力。

\section{1. 畜群结构优化}

在产草量和种群数量一定的情况下, 通过调整 优化畜群结构, 达到适度公母比、成幼比, 使经济 效益最大化。一方面, 在入冬之前将老、弱、病、 
残畜淘汰, 适当补充母牦牛, 从而提高种群越冬能 力, 避免冬季掉膘、死亡; 另一方面, 通过短期育 肥使幼畜快速出栏, 减少公畜比例, 控制种群数量, 可以减少牧草需求量的同时增加牧户收入。

\section{2. 补饲保暖}

针对冬季寒冷、牧草短缺的问题, 在半舍饲条 件下对牲畜采取补饲保暖措施, 以提高家畜越冬能 力。建设适应高寒牧区大风、低温等气候特点的暖 棚, 为牲畜提供越冬场所。采取白天放牧、晚上归 牧圈养的方法，在合理利用冬季牧场的同时减少家 畜能量消耗。选择干草、粗饲料、精料以及营养袑 砖相结合的饲料配方, 对家畜尤其是成年母畜进行 补饲, 提高其体重、繁殖率、泌乳量等生产性能。

\section{（五）藏北高寒畜牧业发展模式}

藏北高原草地畜牧业发展应首先确保生态恢 复，通过退化草地围栏封育、生态补播、节水灌溉 等一系列措施，对退化草地进行综合治理；通过优 化放牧制度和草地管理政策，合理利用草地资源。 着力打造生态产业, 在严重退化草地、牲畜棚圈、 牧户庭院进行高产、优质人工牧草种植; 应用农牧 耦合技术，在低海拔农区进行饲用牧草种植，为高 海拔牧区提供饲草，形成 “低草高牧” 模式。建设 适宜高寒牧区的牲畜棚圈, 进行冬季半舍饲养殖, 加强牲畜越冬能力, 降低死亡率。通过上述一系列 措施, 形成藏北高寒牧区畜牧业 $5: 3: 2$ 发展模式 (以饲草计量) (见图 1)。

通过实施生态治理与畜牧业协同发展模式, 可 以恢复退化草地, 使得草地生产力显著提高、物种 多样性明显增加、水土保持能力大幅提升、生态系
统功能逐步恢复; 优化放牧管理, 因地因时制宜开 展放牧活动, 减轻草地压力的同时达到草场高效利 用; 充分利用牧区庭院、严重退化草地、农区耕地、 盐碱地、滩涂地，建植人工草地，补充高寒牧区饲 草缺口的同时增加低海拔农区收入，促进区域间耦 合联动; 提高牲畜养殖效率，有效解决冬季保暖问 题, 增加肉奶产量, 显著提升高寒畜牧业产业活力。 总之，在藏北高寒牧区施行生态治理与畜牧业协同 发展模式, 有利于保护生态、发展经济、牧民增收, 具有显著的生态、经济和社会效益。

\section{四、结语}

藏北高寒草地是我国重要的生态安全屏障, 也 是高原特色畜牧业生产基地, 其生态功能和生产功 能缺一不可。为扭转高寒草地退化严重威胁国家 生态安全屏障作用、对广大藏族牧民生存发展形 成挑战的不利局面，亟需实施高寒草地生态保护 与畜牧业协同发展战略。相关研究将为治边稳藏、 保障国家生态安全、增加牧民收入提供战略引导 和科技支撑。

在藏北高寒牧区草地生态治理与畜牧业发展技 术研究与模式运用过程中，应重点关注以下方面：

（1）篮选乡土品种，结合生态补播、草场灌溉、 土壤养分管理等技术，集成并推广退化草地稳定恢 复技术体系。

(2) 开展藏北高寒草地生态资产评估, 明确高 寒草地承载力和生态红线, 分区制定高寒草地合理 利用方式, 篮选高寒草地的适宜禁牧年限, 因地制 宜地实施区划轮牧放牧模式。



图 1 藏北高原草地畜牧业发展模式框架 
(3) 推广发展高寒牧区家庭牧场的人工种草, 充分利用房前屋后、牲畜棚圈等闲置空间，研发高 寒牧区家庭人工种草、陉藏、加工技术，形成高寒 牧区高产饲草生产技术体系。

（4）鼓励低海拔农区种植饲用牧草，加强农牧 区域联动，将低海拔农区种草和高海拔牧区养畜相 结合，构建农牧耦合的“低草高牧”模式。

（5）转换 “靠天养畜”的传统放牧方式，在 “以 草定畜”的基础上控制种群数量、优化种群结构, 推行 “幼畜快速出栏” “母畜补饲保暖” 等措施, 示范冬季半舍饲养殖模式, 促进高寒草地畜牧业 转型升级。

\section{参考文献}

[1] 高清竹, 江村旺扎, 李玉娥, 等. 藏北地区草地退化遥感监测与 生态功能区划 [M]. 北京: 气象出版社, 2006.

Gao Q Z, Jiangcun W Z, Li Y E, et al. Remote sensing monitoring and ecological function regionalization of grassland degradation in Northern Tibet [M]. Beijing: Meteorological Press, 2006.

[2] 高清竹, 李玉娥, 林而达, 等. 藏北地区草地退化的时空分布特 征 [J]. 地理学报, 2005, 60(6): 965-973.

Gao Q Z, Li Y E, Lin E D, et al. Temporal and spatial distribution of grassland degradation in Northern Tibet [J]. Acta Geographica Sinica, 2005, 60(6): 965-973.

[3] Ganjurjav H, Gao Q, Gornish E S, et al. Differential response of alpine steppe and alpine meadow to climate warming in the central Qinghai-Tibetan Plateau [J]. Agricultural and Forest Meteorology, 2016, 223: 233-240.

[4] 徐增让, 郑金金, 靳茗茗. 自然保护区土地利用冲突及协调一以 㒸塘国家自然保护区为例 [J]. 科技导报, 2018, 36(7): 8-13.

Xu Z R, Zheng X, Jin M M. Harmonizing conflicts of land multifunction in natural reserves-Qiangtang national natural reserve as an example [J]. Science \& Technology Review, 2018, 36(7): 8-13.

[5] 刘兴元, 王玮. 藏北草地生态系统可持续发展能力评价 [J]. 自 然资源学报, 2013, 28(7): 1209-1220.

Liu X Y, Wang W. Evaluation of rangeland ecosystem sustainability of the Northern Tibetan region, China [J]. Journal of Natural Resources, 2013, 28(7): 1209-1220.

[6] 董世鬼. 高寒地区多年生禾草混播草地群落稳定性及其调控机 制研究 [D]. 兰州: 甘肃农业大学 (博士学位论文), 2001.

Dong S K. The stability of mixture grassland of cultivated perennial grass and its regulation in alpine region of QinghaiTibetan Plateau of China [D]. Lanzhou: Gansu Agricultural University (Doctoral dissertation), 2001.

[7] 魏学红, 杨富裕, 孙否. 补播和施肥对藏北高寒退化草地的改良 效果 [J]. 安徽农业科学, 2010, 38(32): 18155-18156.

Wei X H, Yang F Y, Sun L. Effects of reseeding and fertilization on the vegetation recovery of degraded grassland in North Tibet [J]. Journal of Anhui Agricultural Sciences, 2010, 38(32): 18155-
18156.

[8] 干珠扎布, 段敏杰, 郭亚奇, 等. 喷灌对藏北高寒草地生产力和 物种多样性的影响 [J]. 生态学报, 2015, 35(22): 7485-7493.

Ganjurjav H, Duan M J, Guo Y Q, et al. Effects of irrigation on alpine grassland Northern Tibet [J]. Acta Ecologica Sinica, 2015, 35(22): 7485-7493.

[9] 宗宁, 石培礼, 牛粼, 等. 氮磷配施对藏北退化高寒草甸群落结 构和生产力的影响 [J]. 应用生态学报, 2014, 25(12): 3458-3468. Zong N, Shi P L, Niu B, et al. Effects of nitrogen and phosphorous fertilization on community structure and productivity of degraded alpine meadows in Northern Tibet, China [J]. Chinese Journal of Applied Ecology, 2014, 25(12): 3458-3468.

[10] 段敏杰, 干珠扎布, 郭佳, 等. 施肥对藏北高寒草地植物多样性 及生产力的影响 [J]. 西北农业学报, 2016, 25(11): 1696-1703.

Duan M J, Ganjurjav H, Guo J, et al. Effects of fertilization on plant diversity and productivity of alpine meadow in Northern Tibet [J]. Acta Agriculturae Boreali-occidentalis Sinica, 2016, 25(11): 1696-1703.

[11] Bowman W D, Cleveland C C, Ĺuboš Halada, et al. Negative impact of nitrogen deposition on soil buffering capacity [J]. Nature Geoscience, 2008, 1(11): 767-770.

[12] 秦燕, 何峰, 全宗永, 等. 施肥对羊草草原土壤氮素转化的影响 [J]. 草业学报, 2016, 25(10): 48-55.

Qin Y, He F, Tong Z Y, et al. Influence of fertilizer use on nitrogen transformation in soils of the Leymus chinensis steppe [J]. Acta Prataculturae Sinica, 2016, 25(10): 48-55.

[13] 肖金玉, 蒲小鹏, 徐长林. 禁牧对退化草地恢复的作用 [J]. 草业 科学, 2015, 32(1): 138-145.

Xiao J Y, Pu X P, Xu C L. Effects of grazing prohibition on restoration of degraded grassland [J]. Pratacultural Science, 2015, 32(1): 138-145.

[14] Wu J, Zhang X, Shen Z, et al. Species richness and diversity of alpine grasslands on the Northern Tibetan Plateau: Effects of grazing exclusion and growing season precipitation [J]. Journal of Resources and Ecology, 2012, 3(3): 236-242.

[15] 张伟娜. 不同年限禁牧对藏北高寒草甸植被及土壤特征的影响 [D]. 北京: 中国农业科学院 (硕士学位论文), 2015.

Zhang W N. The plant and soil characteristics of the alpine meadow under different period of grazing ban in Northern Tibet [D]. Chinese Academy of Agricultural Sciences (Master's thesis), 2015.

[16] 马玉寿, 李世雄, 王彦龙, 等. 返青期休牧对退化高寒草甸植被 的影响 [J]. 草地学报, 2017, 25(2): 290-295.

Ma Y S, Li S X, Wang Y L, et al. Effect of rest-grazing in the greenup period on degraded vegetation in alpine meadow [J]. Acta Agrestia Sinica, 2017, 25(2): 290-295.

[17] Ganjurjav H, Duan M, Wan Y, et al. Effects of grazing by large herbivores on plant diversity and productivity of semi-arid alpine steppe on the Qinghai-Tibetan Plateau [J]. The Rangeland Journal, 2015, 37(4): 389-397.

[18] 马玉寿, 张自和, 董全民, 等. 恢复生态学在“黑土型”退化草地 植被改建中的应用 [J]. 甘肃农业大学学报, 2007, 42(2): 91-97. Ma Y S, Zhang Z H, Dong Q M, et al. Application of restoration ecology in "black soil type" degraded grassland rebuilding [J]. Journal of Gansu Agricultural University, 2007, 42(2): 91-97. 